\title{
Integration and Test Methods of Energy-saving Electronic 10kV Metering Device
}

\author{
Q.F. SHANG, Y.J. LI \& Q.Q. CHEN \\ Electronics and Communication Engineering, North China Electric Power University, Baoding 071003, \\ China
}

\begin{abstract}
Designed in this paper, the energy-saving electronic $10 \mathrm{kV}$ metering device is composed of electronic voltage transformer, electronic current transformer, electronic metering terminal and communication terminal. Electronic transformers and metering terminal are no longer designed and tested independently. Based on the principle of minimum overall error of $10 \mathrm{kV}$ electricity metering device, the partial pressure ratio of $10 \mathrm{kV}$ volt-age divider network, the ratio of electronic current transformer and currentvoltage conversion, the influence of the stray capacitance generated after electronic transformer and metering terminal are packaged in the circuit breaker box, should be coordinated in integrated design consideration, based on input range and calibration capability of measurement chip. And the $10 \mathrm{kV}$ metering device is tested with integration method. This article describes the device structures and calibrating methods. The test results show that the active power accuracy class of the device designed in this paper is 0.5 , and that reactive power accuracy class is 2.0. The developed device with low power consumption advantages and three-phase fourwire connection mode, resolved line loss problem due to the unbalanced load.
\end{abstract}

KEYWORD: $10 \mathrm{kV}$ measurement; electronic voltage transformer; electronic current transformer; integration; error uncertainty

\section{INTRODUCTION}

In China, the transformer uses three-phase threewire connection mode in high-voltage (HV) side while using three-phase four-wire connection mode in low-voltage side in the condition of $10 \mathrm{kV}$ high voltage wire using neutral non-effective grounding. The traditional electromagnetic $10 \mathrm{kV}$ metering devices are installed in HV side, using the threephase three-wire measurement model. The electric energy results are accurate relatively in the condition of three-phase balance load (BU Zhengliang et al., 2006). However, in the case of three-phase unbalance, metering electric energy and user's energy consumption are not equal, that will lead to inaccurate measurement, even active power is not measured. Users may steal power through a threephase three wire measurement model of the vulnerability. And due to the serious imbalance of the line load, there will be a serious loss.

The developed device using three-phase fourwire connection mode can measure the full information (current, voltage) of three-phase on line. The measurement can be carried out without leakage phase, and micro electricity consumption can be metered. Accordingly, the device can measure the power energy more accurately and has the function of anti-stealing electric energy.

Energy-saving electronic $10 \mathrm{kV}$ metering device consists of electronic transformers, metering terminal and communication terminal. Low power current transformer and resistor divider voltage transformer outputting the weak analog voltage signal proportioned with the primary current and voltage, can connect with metering terminal seamlessly. Electronic transformer almost does not consume energy, but also can save a large amount of iron and copper, with light weight, low power consumption, advantages of energy-saving and loss reduction, in line with the national energy-saving emission reduction and green environmental protection requirements (LI Jiuhu et al. 2007).

This paper introduces methods of integration error testing and uncertainty evaluation and the seamless integration between electronic transformers and metering terminal which is the way to improve the measurement accuracy of the device.

\section{SYSTEM COMPOSITION}

In this context, the main elements of energy-saving electronic $10 \mathrm{kV}$ metering device, depicted in the 
block diagram of Fig.1, include: electronic transformers, electronic metering terminal and communication terminal. By use of electronic voltage transformer and current transformer, the device transferred high voltage and large current signal into little volt voltage signals and mill amperes current signals which were sent directly to the measurement terminal for data processing. And the energy parameters obtained were transmitted by RS485 to the communication terminal finally. The electronic transformers and metering terminal were packed in the circuit breaker box hanged on the top of the pole for anti-stealing electric energy. And the communication terminal used for meter reading staff and users to check the data was put in the bottom of the pole. Simultaneously, the communication terminal has the function of the local power parameters displaying and remote data transmission. The device using a $50 \mathrm{M} \Omega \mathrm{HV}$ resistance between with phase and ground, did not affect the connection mode of $10 \mathrm{kV}$ system.

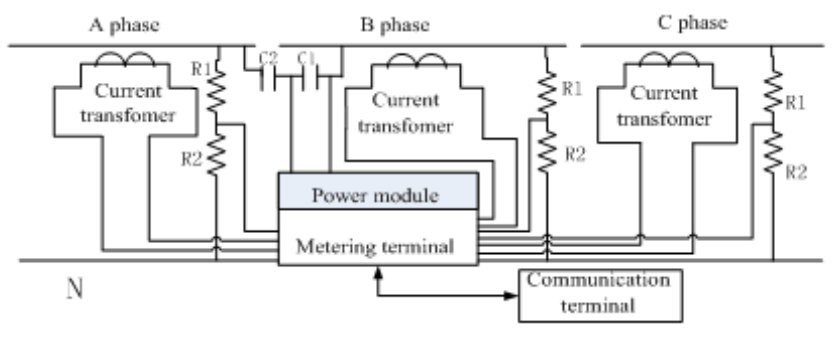

Figure 1. Block diagram for metering device system

\subsection{Metering Terminal}

The metering terminal shown as Fig.2, consisted of the following sections: pre-processing circuit, ADE7878, MCU, ferroelectric memory, RS232/485, real time clock (RC) and power module, etc. The metering terminal calculated power parameters, then transmitted data to display terminal. ADE7878 can calibrate the phase and amplitude offset of electronic transformer within a certain range.

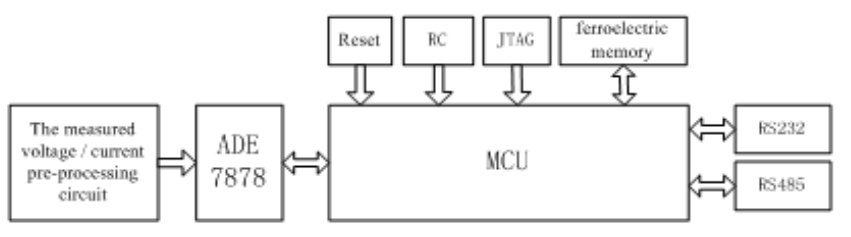

Figure 2. Block diagram for metering terminal

The high voltage and large current signals from $10 \mathrm{kV}$ high-voltage grid were converted by the preprocessing circuit into $\mathrm{mV}, \mathrm{mA}$ level signals transmitted to ADE7878. The data were processed and stored in internal registers of ADE7878, The LPC2368 microcontroller could read current, voltage, power, electric energy and other data via the serial port. RS232 was used to automatic calibration of the device and RS485 was for remote meter reading.

\subsection{HV Energy Supply Module}

The design of HV energy supply module uses the principle of capacitive voltage divider. The line voltage instead of phase voltage as supply ensured that the accuracy of the phase voltage measurement is not affected.

By selecting the proper capacitance value, the voltage divider output was controlled within $83 \mathrm{~V} \sim 154.2 \mathrm{~V}$ with the $10 \mathrm{kV}$ voltage fluctuation range $7 \sim 13 \mathrm{kV}$, because the measurement terminal voltage input range was $80 \mathrm{~V} \sim 265 \mathrm{~V}$. The pressure value of the high voltage capacitor is chosen as $50 \mathrm{kV}$, which meted the $42 \mathrm{kV}$ requirement of $10 \mathrm{kV}$ equipment.

\section{INTEGRATED DESIGN METHOD}

The so-called integrated design method means that electronic transformers and metering terminal are no longer designed independently, tested independently. Based on the principle of minimum overall error of $10 \mathrm{kV}$ electricity metering device, the partial pressure ratio of $10 \mathrm{kV}$ voltage divider network, the ratio of electronic current transformer and current-voltage conversion, the influence of the stray capacitance generated after electronic transformer and metering terminal are packaged in the circuit breaker box, should be coordinated in integrated design consideration, based on input range and calibration capability of measurement chip. The calibration flow chart of the ADE7878 gain registers and offset registers is shown in Fig. 3.

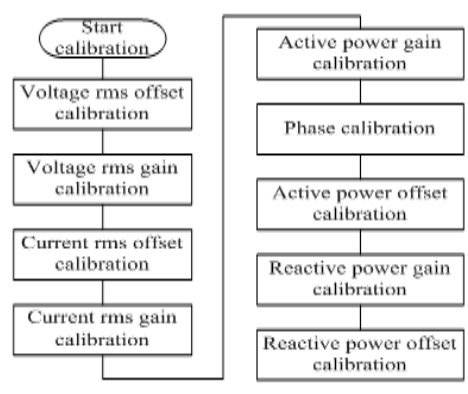

Figure 3. Calibration flow chart

\section{INTEGRATION TESTING ERROR AND UNCERTAINTY ANALYSIS}

\subsection{Independent Test}

In this context, the technical indicators of energysaving electronic $10 \mathrm{kV}$ metering device are: voltage: $3 * 5.77 \mathrm{kV}$, current:5 500A, frequency: 
$(50 \pm 2.5) \mathrm{Hz}$, power: $<6 \mathrm{~W}$, voltage accuracy class: 0.2 , current accuracy class: $0.2 \mathrm{~S}$, active power accuracy class: 0.5 , reactive power accuracy class: 2.0 .

According to IEC60044-7/8, the evaluation of electronic transformers was completed in Xi'an High Voltage Apparatus Research Institute in 2013. And voltage measurement accuracy class is 0.2 , the current measurement accuracy class is $0.2 \mathrm{~S}$. Specific testing projects include the followings: accuracy test, the accuracy of the temperature-cycle test, power-frequency voltage withstand of primary side test, partial discharge measurement, rated lightningimpulse test, truncated lightning impulse test, shorttime current tests, ECT temperature-rise test and experiment on the relationship between accuracy and frequency. Electronic voltage transformer rated output is $2 \mathrm{~V}$. Electronic current transformer rated output is $10 \mathrm{~mA}$ which is converted to the rated voltage output $4 \mathrm{~V}$ after $1 / 10000$ precision resistors.

The terminal measurement accuracy test using the comparison method was completed in Baoding, Hebei Province, the metrology Supervision Bureau. Calibration device is the CL303 programmable three-phase power source whose signal $(100 \mathrm{~V} / 5 \mathrm{~A})$ were connected with the measurement terminal through $1 / 10000$ precision class metering transformers. The standard meter is CL311V2 threephase multi-function meter whose accuracy class is 0.05 . Then, the output of calibration device was set to the rated voltage. The output current was adjusted to $0.2 \mathrm{Ib}, 1.0 \mathrm{Ib}, 4.0 \mathrm{Ib}$ in turn. The output power factor was adjusted to $1.0,0.5 \mathrm{~L}, 0.8 \mathrm{C}$. The electric Energy measurement accuracy of the test measurement terminal was obtained by comparing the active energy pulses output of the test meter and the standard meter. The experimental results show that the error of the test measurement terminal reaches the design requirements in this article.

\subsection{Integration Test Approach}

According to the basic principles of the International Electrotechnical Commission (IEC) : The error of all instrumentation and measuring devices must be actual measurement. Without measurement, the error just based on other measurements and calculated error voltage, current and power factor reference combination, cannot be used as the basis for evaluating the basic error of the device (Wei, J. et al .2014). Assuming the accuracy rating of the current transformers, voltage transformers and meter are 0.2 , integrated permissible error of metering device is estimated to be $0.7 \%$. Now the defect of using this estimation method is: current transformers are working in a HV side, and tested in low voltage; combination transformer is working in the state of three-phase, but only tested in single phase (Zhang fuzhou et al. 2014). So the metering device should be calibrated integrally and uncertainty should be assessed entirely. Verification platform for testing in this paper is shown as Fig.4.

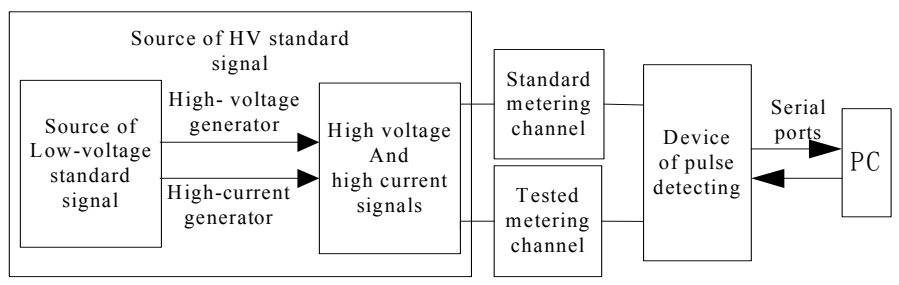

Figure 4. Verification platform diagram

\subsection{Uncertainty Evaluation of Testing Error}

In standard channel system, the accuracy rating of standard voltage transformer and current transformer are class 0.01 , and the accuracy rating of standard meter is 0.1 . The data of Table 1 is active error which tested under the condition of different power factor and current which is set respectively $100 \%, 50 \%, 20 \%, 10 \%, 5 \%$ of the rated current(Ib). When the current is $100 \%$ of the rated current(Ib), the data of the reactive error is 0.063 and 0.220 respectively under the condition of the power factor 1.0 and $0.5 \mathrm{~L}$.

Table 1. Active error

\begin{tabular}{|c|c|c|c|c|c|}
\hline $\begin{array}{c}\mathrm{Ib} \% \\
\cos \varphi\end{array}$ & $\begin{array}{c}100 \% \\
{[\%]}\end{array}$ & $\begin{array}{c}50 \% \\
{[\%]}\end{array}$ & $\begin{array}{c}20 \% \\
{[\%]}\end{array}$ & $\begin{array}{c}10 \% \\
{[\%]}\end{array}$ & $\begin{array}{c}5 \% \\
{[\%]}\end{array}$ \\
\hline 1.0 & 0.0143 & 0.0096 & 0.0266 & 0.0419 & 0.0936 \\
\hline $0.8 \mathrm{C}$ & 0.148 & 0.1372 & 0.1307 & 0.1497 & 0.2009 \\
\hline $0.5 \mathrm{~L}$ & -0.3276 & -0.2884 & -0.1784 & -0.1394 & -0.0316 \\
\hline
\end{tabular}

\section{CALCULATION AND ANALYSIS OF CALIBRATION DEVICE UNCERTAINTY}

Uncertainty Evaluation methods include Class A, Class B uncertainty, standard uncertainty and expanded uncertainty.

Class A uncertainty U(r01): Uncertainty of each component can be described by the standard deviation $\mathrm{S}$ which used a limitednumber of experimental standard deviation $\mathrm{S}$ calculated by Bessel formula: $s=\sqrt{\frac{\sum_{i=1}^{n}(x-\bar{x})^{2}}{n-1}}$.

Table 2. Relative error

\begin{tabular}{|c|c|c|c|c|c|}
\hline $\begin{array}{r}\mathrm{Ib} \% \\
\text { Times }\end{array}$ & $\begin{array}{c}100 \% \\
{[\%]}\end{array}$ & $\begin{array}{c}50 \% \\
{[\%]}\end{array}$ & $\begin{array}{c}20 \% \\
{[\%]}\end{array}$ & $\begin{array}{c}10 \% \\
{[\%]}\end{array}$ & $\begin{array}{c}5 \% \\
{[\%]}\end{array}$ \\
\hline 1 & -0.344 & -0.291 & -0.298 & -0.289 & -0.309 \\
\hline 2 & -0.329 & -0.275 & -0.288 & -0.277 & -0.318 \\
\hline 3 & -0.313 & -0.287 & -0.301 & -0.294 & -0.305 \\
\hline 4 & -0.329 & -0.292 & -0.303 & -0.279 & -0.310 \\
\hline
\end{tabular}




\begin{tabular}{|c|c|c|c|c|c|}
\hline 5 & -0.329 & -0.274 & -0.299 & -0.288 & -0.307 \\
\hline 6 & -0.329 & -0.292 & -0.311 & -0.298 & -0.311 \\
\hline 7 & -0.313 & -0.297 & -0.304 & -0.302 & -0.307 \\
\hline 8 & -0.317 & -0.288 & -0.299 & -0.279 & -0.324 \\
\hline 9 & -0.329 & -0.288 & -0.294 & -0.292 & -0.316 \\
\hline 10 & -0.344 & -0.292 & -0.302 & -0.288 & -0.312 \\
\hline$X$ & -0.328 & -0.288 & -0.300 & -0.289 & -0.312 \\
\hline $\mathrm{S}$ & -0.0110 & -0.0075 & -0.0099 & -0.0084 & -0.0059 \\
\hline
\end{tabular}

As shown in Table 2, the data are error data, average value and experimental standard deviation measured under the condition of $\cos \varphi=0.5 \mathrm{~L}$, rated voltage and current which is set respectively $100 \%$, $50 \%, 20 \%, 10 \%, 5 \%$ of the rated current(Ib).

Standard deviation of the synthetic samples:

$$
S_{P}=\sqrt{\frac{\sum_{m} S^{2}}{m}}=0.0087 \%
$$

Sandard uncertainty:

$U_{(r 01)}=S_{P} / \sqrt{n}=0.0028 \%$

Class B uncertainty $\mathrm{U}(\mathrm{r} 02): U_{(r 02)}=\sqrt{\sum_{j=1}^{n}\left(c_{j} u_{j}\right)^{2}}$

Firstly, the distribution coefficient $\mathrm{kj}$ of each component and the sensitivity coefficient cj were obtained. And then Class B Uncertainty were calculated. The uncertainty components of the standard electric energy meter error and voltage and current transformer error are uniformly distributed. And the value of the distribution coefficient $\mathrm{kj}$ is $\sqrt{3}$, the value of the sensitivity coefficients cj is 1 . The error terms of Class B uncertainty were shown in Table 3:

Table 3. Uncertainty errors of class B

\begin{tabular}{|c|c|c|c|c|c|}
\hline NO. & $\begin{array}{l}\text { Source of } \\
\text { uncertainty }\end{array}$ & $b j^{*}$ & $\mathrm{kj}^{*}$ & $\mathrm{cj}^{*}$ & $u j=b j / k j(\%)$ \\
\hline 1 & $\mathrm{rr}^{*}$ & $0.1 \%$ & $\sqrt{3}$ & 1 & 0.0577 \\
\hline 2 & $\mathrm{fTV}^{*}$ & $0.01 \%$ & $\sqrt{3}$ & 1 & 0.0058 \\
\hline 3 & $\mathrm{fTA}^{*}$ & $0.01 \%$ & $\sqrt{3}$ & 1 & 0.0058 \\
\hline
\end{tabular}
distribution coefficient; $\quad c_{j}$ represents sensitivity coefficient $r_{r}$ represents Standard meter error; fTV represents Standard voltage transformer error; fTA

$$
U_{(r 02)}=\sqrt{U_{1}^{2}+U_{2}^{2}+U_{3}^{2}}=0.0583 \%
$$

represents Standard current transformer error.

Standard uncertainty:

Combined standard uncertainty $\mathrm{UC}_{\mathrm{C}}$ : $U_{C}=\sqrt{U_{(r 01)}^{2}+U_{(r 02)}^{2}}=0.0584 \%$

Expanded uncertainty $\mathrm{U}: U=K U_{C}$

Coefficient $\mathrm{K}$ is the confidence factor, also known as the inclusion factor. In the standard device of the electric energy meter, the value of $\mathrm{K}$ was generally taken 2 and confidence rate (P) was $95 \%$. So the value of Expanded uncertainty is:

$\mathrm{U}=2 * 0.0584 \%=0.1168 \%$.

The best estimate of error $\left(\overline{\varepsilon_{r}}\right)$ can be calculated by relative error:

$$
\overline{\varepsilon_{r}}
$$

( $0.328 \%+0.288 \%+0.300 \%+0.289 \%+0.312 \%$ ) $\div 5=0.3034 \%$.

The energy relative error $\left(\varepsilon_{\mathrm{r}}\right)$ is represented by synthetic error $\left(\varepsilon_{r}\right): \varepsilon_{r}=(0.3034 \pm 0.0584) \%$.

The energy relative error $\left(\varepsilon_{r}\right)$ can be indicated by expanded uncertainty: $\varepsilon_{r}=(0.3034 \pm 0.1168) \%$.

\section{SUMMARY}

The developed device using three-phase four-wire connection mode has the advantages of energy saving, materials saving and small size and antistealing electric energy. The measurement accuracy of the device was improved by using the seamless integration methods and the integrated verification methods. The metering device in the paper was tested by the integrated verification platform of Power supply Company metering chamber in Tangshan City. And measurement results show that energy-saving electronic $10 \mathrm{kV}$ metering device meets the design requirements of active power accuracy class: 0.5 and reactive power accuracy class: 2.0 .

\section{REFERENCES}

BU Zhengliang et al.2006. Development of HV Watt-hour Meter. Automation of Electric Power Systems, 30(19)

Guo L. et al. 2009. On-line calibration of energy metering device based on high voltage energy meter. Electric Power Automation Equipment, 29(12), 79-82.

LI Jiuhu et al. 2007. Application of Electronic Instrument Transformer in Digital Substation. Automation of Electric Power Systems, 31(7), 94-98.

Rong Bo. 2009.Sensor-based HV electric energy meter and its application. 20th International Conference on Electricity Distribution, 8(11).

Wei, J. et al .2014. Research on three-phase calibration method of hv three- phase combined transformer and its implementation. Electrica 1Measurement \& Instrumentation, 568-570, 1191-1195.

Yue C. X. et al. 2010. Calibration of Integrated Error Verification Equipment for $10 \mathrm{kV}$ High Voltage Electrical Energy Measurement Device.Electrical Measuremen \& Instrumentation. 47(A07),132-136.

Zhang fuzhou et al. 2014. Impact of wring of three-phase combined transformer three-phase verification method on accuracy// Chinese Society of Electrical Engineering of the 13th Youth Conference Proceedings.

Zhang N. et al. 2012. Three-phase combined transformer calibration device research. Automation \& Instrumentation. 